\title{
Distribution of Coronary Artery Anomalies and Their Evaluation with Different Imaging Modalities
}

\author{
Raval A ${ }^{1}$, Jadhav $\mathbf{N}^{2}$, Prajapati $\mathbf{J}^{3}$, Rawal $\mathbf{J}^{4}$, Garg $\mathbf{R}^{5}$, Shah $\mathbf{K}^{6}$, Patel $\mathbf{I}^{7}$ \\ ${ }^{1}$ Dr Abhishek Raval, Assistant professor, U.N. Mehta Institute of Cardiology and Research Centre (UNMICRC), \\ Ahmedabad, India, ${ }^{2}$ Dr Nikhil Jadhav, Assistant professor, U.N. Mehta Institute of Cardiology and Research Centre \\ (UNMICRC), Ahmedabad, India, ${ }^{3}$ Dr Jayesh Prajapati, Professor in Cardiology, U.N. Mehta Institute of Cardiology and \\ Research Centre (UNMICRC), Ahmedabad, India, ${ }^{4}$ Dr Jayesh Rawal, Interventional cardiologist, Ahmedabad, India, ${ }^{5}$ Dr \\ Rajiv Garg, Interventional cardiologist, SPS Hospitals, Ludhiana, Punjab, India, ${ }^{6}$ Komal Shah, Research Officer, U.N. \\ Mehta Institute of Cardiology and Research Centre (UNMICRC), Ahmedabad, India, ${ }^{7}$ Iva Patel, Research fellow, U.N. \\ Mehta Institute of Cardiology and Research Centre (UNMICRC), Ahmedabad, India.
}

Address for Correspondence: Abhishek Raval, E-602, Shilalekh Towers, Opp. Police Stadium, Shahibaug, Ahmedabad- 380004, India. E mail: docabs4u@gmail.com

\begin{abstract}
Introduction: Coronary artery anomalies (CAA) are diverse abnormalities. Methods: A retrospective review of coronary imaging of 17,245 patients over 2 years was performed. Patients with CAA detected on echocardiography, invasive coronary angiography (CAG) and multidetector computed tomographic angiography (MDCTA) were compared. Results: CAAs were detected in 257 patients (1.49\%). Prevalence were: absent left main trunk- 0.319\%, anomalous coronary artery from opposite sinus (ACAOS)- $0.516 \%$, coronary fistulae- $0.203 \%$, myocardial bridge- $0.093 \%$, malignant anomalies- $0.3 \%$. The commonest CAA was absent left main trunk. The yield of echocardiography negatively correlated with age $(\mathrm{r}=-0.6)$. CAG and MDCTA were equal $(\mathrm{p}=1)$ for detection of absent left main trunk. CAG had low sensitivity $(58.3 \%)$ and MDCTA was better than it $(\mathrm{p}<0.01)$ for detection of abnormal high origin. For ACAOS, detection by both were not different $(\mathrm{p}=0.5)$ but the course was delineated better with MDCTA than with $\mathrm{CAG}(\mathrm{p}=0.05)$. Both were equal for detection of intramyocardial course $(\mathrm{p}=0.5)$. However, MDCTA delineated its course better than CAG ( $\mathrm{p}<0.01)$. Echocardiography had 93\% sensitivity for fistula in those <12 years in age. Radiation exposure with CAG, $7.3 \pm 2 \mathrm{mSv}$, was lower than that with MDCTA, $14.5 \pm 3 \mathrm{mSv}(\mathrm{p}<0.01)$. It correlated with CAA score ( $\mathrm{r}=0.3)$, with CAG but not with MDCTA. Contrast exposure correlated with CAA score $(r=0.4)$ for adults with CAG but not with MDCTA. Conclusion: Echocardiography reliably detects CAAs in children. CAG and MDCTA are comparable for detection of most CAA. MDCTA delineates the course better than CAG. For MDCTA, radiation exposure is not correlated with complexity of CAA in contrast to that with CAG.
\end{abstract}

Key words: Coronary artery anomalies; Echocardiography; Coronary Angiography; Computed Tomography; Radiation Exposure

\section{Introduction}

Coronary artery anomalies (CAA) are rare congenital conditions with an incidence ranging from $0.17 \%$ in autopsy cases to $1.2 \%$ in angiographically evaluated cases [1-3]. Most of these CAAs are not clinically important. However, nonfatal or fatal acute myocardial

Manuscript received $27^{\text {th }}$ September 2016

Reviewed: $05^{\text {th }}$ October 2016

Author Corrected: $14^{\text {th }}$ October 2016

Accepted for Publication $26^{\text {th }}$ October 2016 infarction can occur in such patients, like those patients with Anomalous Coronary Artery from the Opposite Sinus (ACAOS) notably among young athletes [1,4-6]. In some cases the aberrant vessel, which passes between the aorta and the main pulmonary artery, can cause a sudden death [1]. Echocardiography is a non-invasive tool for detection of CAAs especially in pediatric population. Its usefulness in adults is limited by 
acoustic factors. CAAs are evaluated with catheter based coronary angiography (CAG), which is known as a gold standard [1]. Contrast-enhanced electron beam computed tomography (EBCT) offers excellent spatial resolution and identifies most of the course anomalies
[1,7]. Multidetector row-computed tomography (MDCT) is a new imaging technique. Its importance is gradually increased in the area of cardiac imaging [1]. Magnetic resonance imaging (MRI) has often been used to determine the CAA in equivocal cases.

\section{Materials and Methods}

Retrospective review of 17,245 patients, who underwent coronary imaging at our institute over consecutive 2 years was performed. Indications for evaluation included angina, dyspnea, syncope or cyanosis. Patients diagnosed to have any CAA were retrospectively included in the study.

All patients underwent transthoracic echocardiography (iE33 xMATRIX, Philips Healthcare, Andover, USA). Invasive CAG was performed in flat-panel cath-labs (Philips Medical systems, Nederland B.V.) under mono-plane fluoroscopy from femoral or radial arterial route.

(Figure-1) Absent left main trunk was revealed on left coronary angiogram with left anterior oblique view with caudal angulation. The anomalous course of ACAOS was determined on the basis of 'dot' and 'eye' signs in right anterior oblique view. Intra-myocardial course was detected on the basis of systolic constriction of the particular vessel. Coronary fistulae were detected from visualization of communication of coronary artery with any chamber.

\section{Figure 1: Invasive coronary angiograms showing coronary anomalies}

A: Left anterior view showing left coronary artery $(*)$ arising from right sinus of valsalva with anterior course

B: Right anterior oblique view showing right coronary artery (*) arising from left sinus of valsalva with interarterial course

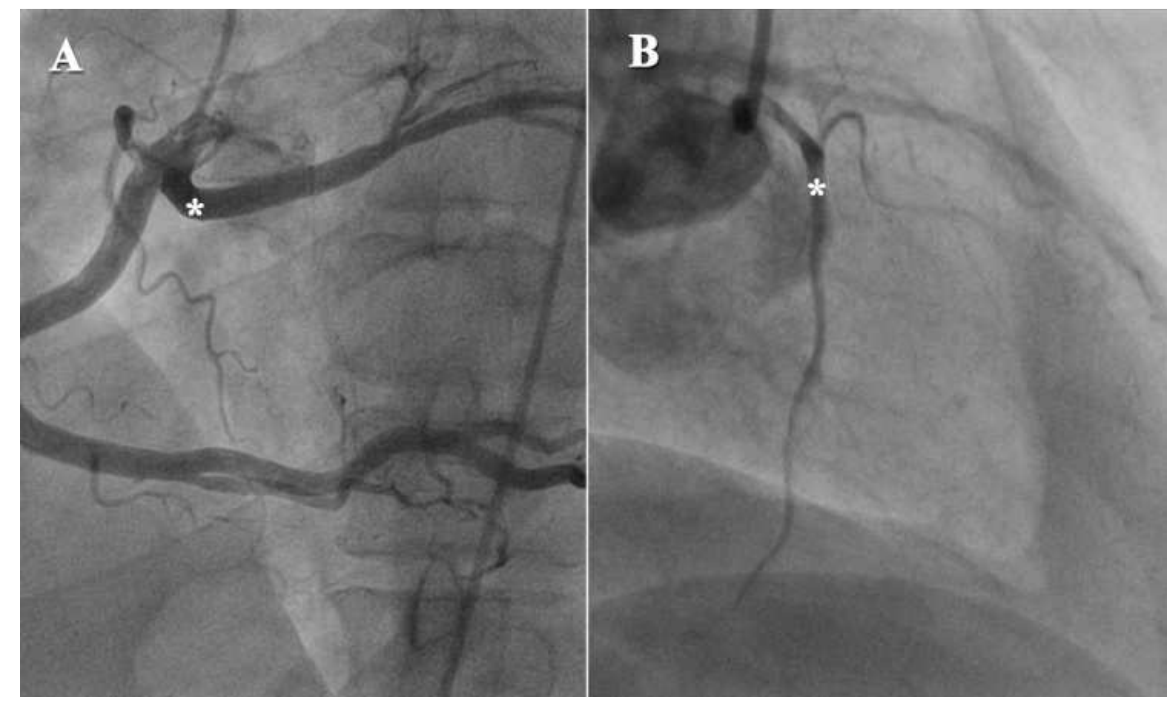

Patients underwent MDCT angiography (MDCTA), performed with 128 slice MDCT scan (Somatom definition AS+ CT scanner machine, Siemens Healthcare, Malvern, USA). A native, prospectively electrocardiogram (ECG)-triggered scan for coronary artery calcium scoring was followed by a contrast-enhanced, retrospectively ECG-gated coronary MDCTA. Out of initially obtained raw-data sets, standardized image reconstructions were performed at $25 \%, 45 \%$, and $65 \%$ of the RR-Interval, respectively and, if necessary, additional reconstructions throughout the whole cardiac cycle were performed.

All acquired MDCTA images were transferred to a dedicated CT 3-dimensional post-processing workstation (Leonardo, Siemens Healthcare, Malvern, USA). Axial and curved multiplanar reformatted images, Maximum Intensity Projections, and Volume Rendered images were analyzed for the determination of the origin and course of coronaries, the take-off angles from the aorta, and size of the orifice. (Figure-2) 
Figure-2: Volume rendered 3-dimensional Multidetector computed tomographic angiogram images showing coronary anomalies

A: Left circumflex artery (*) arising from right sinus of valsalva with retroaortic course

B: Right coronary artery $(*)$ arising from left sinus of valsalva with interarterial course

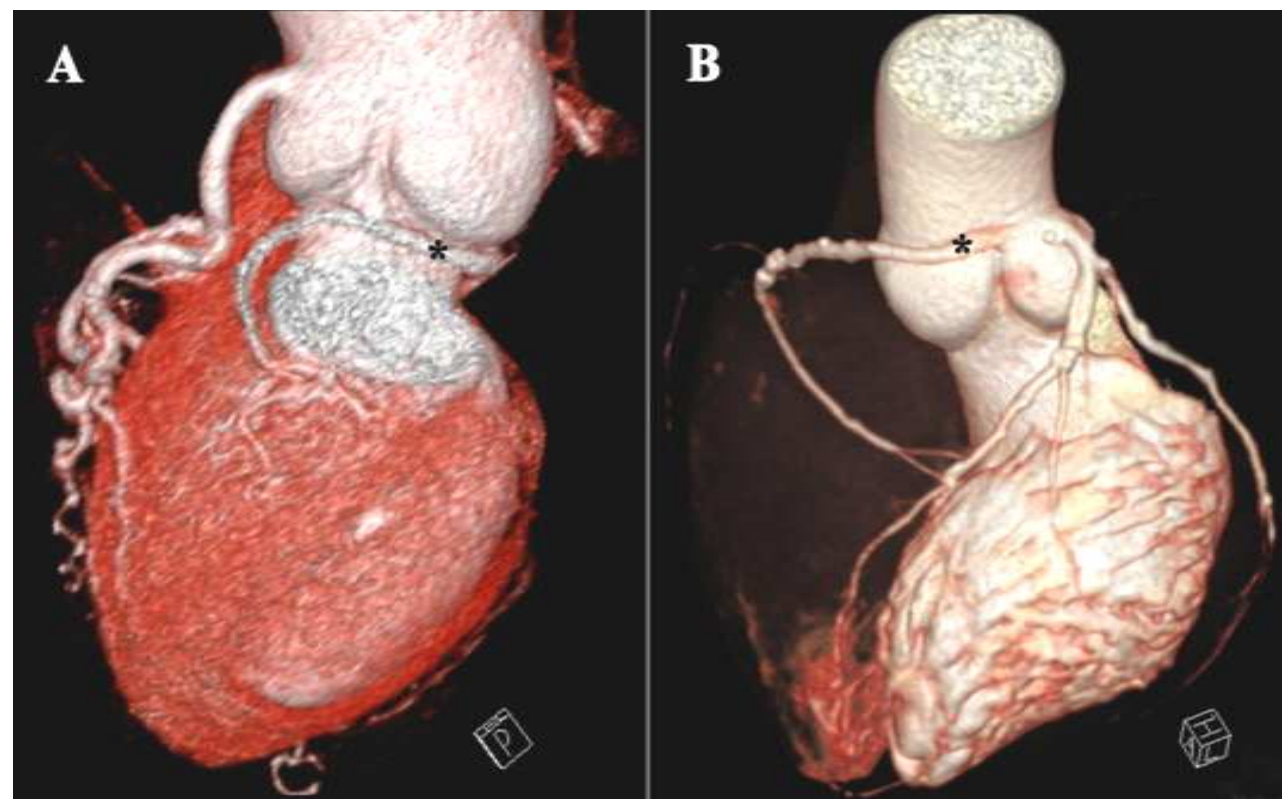

According to Angelini, 2007,[8] CAAs were defined and classified depending on anomalous origin and vessel course and the dependent myocardial territory. In addition to anatomical classification, anomalies were classified according to functional classification in benign and malignant types. Scoring of anomalies was performed according to Rigatelli et al. 2012[9].

Statistical analysis- Continuous data were expressed as mean \pm standard deviation (SD), and were compared using the Student paired- t-test (2-tailed). Categorical variables were expressed as percentages, and were compared ( $\mathrm{p}$-values) using the Chi-square test with Yates correction or Fisher's exact test. A p-value $<0.05$ was considered to indicate significant difference. Pearson's correlation analysis was used to explore correlations (r) between CAA score, radiation exposure, contrast expenditure etc. All statistical calculations were performed with SPSS software (IBM VERSION 20, Chicago, USA).

\section{Results}

Prevalence-A total of 17,245 coronary artery evaluations were performed, of which 257 were found to have CAAs, at a prevalence rate of $1.49 \%$.

Age Distribution- The commonest anomaly detected in infants was Anomalous Left Coronary Artery from Pulmonary Artery (ALCAPA) (26.7\% of CAAs in that age-group). The commonest anomaly in pediatric age group (1-12 years) was coronary artery fistula (52\%). The commonest anomaly in the entire pediatric age group (<12 years) was ACAOS (42\% of CAAs of that age-group). The second most common CAA in pediatric age group was coronary artery fistula (37.5\%). The commonest anomaly in young adults (12-40 years) was anomalous high origin of coronary artery from same sinus. The commonest anomaly in elderly population (>40 years) was anomalous separate origin of Left Anterior Descending artery (LAD) and Left Circumflex artery (LCX) from Left Sinus of Valsalva (LSV) (29.7\% of anomalies in that agegroup) followed by anomalous origin of LCX from Right Sinus of Valsalva (RSV) (17.58\%).

Sex Distribution-From 17,245 patients; 12,608 were male, out of which 194 had CAAs. Sixty-three females out of 4637 had CAAs. The prevalence of CAAs in males was $1.538 \%$ and prevalence in females was $1.359 \%$. The difference between the prevalence in two genders was statistically insignificant $(\mathrm{p}=0.43)$. 
Association with other congenital anomalies-In 28 patients (10.89\%), the CAAs were associated with other congenital heart diseases (CHD). In 229 patients (89.12\%) it was not associated with any CHD. Association with other CHD was extremely significantly higher in pediatric population as compared to that in adults $(\mathrm{p}<0.0001)$.

Anatomical Classification-Distribution and prevalence of all types and subtypes of coronary anomalies was as per Table-1. Nine patients had more than one type of CAAs. The commonest anomaly was separate origin of LAD and LCX from LSV $(0.319 \%)$. Second commonest one was anomalous origin of LCX from RSV $(0.231 \%)$. The third commonest anomaly was coronary fistula $(0.203 \%)$.

Table-1: Distribution and prevalence of all subtypes of coronary anomalies

\begin{tabular}{|c|c|c|c|c|c|c|}
\hline \multicolumn{5}{|l|}{ Anomaly } & Frequency & $\begin{array}{l}\text { Prevalence } \\
(\%)\end{array}$ \\
\hline \multicolumn{4}{|c|}{ Anomalies of origination and course } & A & 202 & 1.171 \\
\hline \multicolumn{4}{|l|}{ Absent left main trunk } & A1 & 55 & 0.319 \\
\hline \multirow{2}{*}{$\begin{array}{l}\text { Anomalous location of } \\
\text { coronary ostium within aortic } \\
\text { root or near proper aortic sinus } \\
\text { of Valsalva (for each artery) }\end{array}$} & \multicolumn{3}{|l|}{ High } & $\mathrm{A} 2 \mathrm{a}$ & 31 & 0.180 \\
\hline & \multicolumn{3}{|l|}{ Low } & $\mathrm{A} 2 \mathrm{~b}$ & 4 & 0.023 \\
\hline \multirow{6}{*}{$\begin{array}{l}\text { Anomalous location of } \\
\text { coronary ostium outside } \\
\text { normal coronary aortic sinuses }\end{array}$} & \multicolumn{3}{|l|}{ PSV } & A3a & 14 & 0.081 \\
\hline & \multicolumn{3}{|c|}{ ascending aorta } & $\mathrm{A} 3 \mathrm{~b}$ & 3 & 0.017 \\
\hline & \multirow{4}{*}{\multicolumn{2}{|c|}{ PA }} & LCA & A3e1 & 5 & 0.029 \\
\hline & & & LAD & A3e3 & 0 & 0 \\
\hline & & & LCX & $\mathrm{A} 3 \mathrm{e} 2$ & 1 & 0.006 \\
\hline & & & RCA & A3e4 & 0 & 0 \\
\hline \multirow{10}{*}{$\begin{array}{l}\text { Anomalous location of } \\
\text { coronary ostium at improper } \\
\text { sinus }\end{array}$} & \multirow{2}{*}{\multicolumn{2}{|c|}{$\begin{array}{l}\text { RCA that arises } \\
\text { from LSV }\end{array}$}} & $\begin{array}{l}\text { Course between } \\
\text { aorta and PA }\end{array}$ & $\mathrm{A} 4 \mathrm{a} 3$ & 26 & 0.151 \\
\hline & & & $\begin{array}{l}\text { Course anterior to } \\
\text { PA }\end{array}$ & $\mathrm{A} 4 \mathrm{a} 5$ & 4 & 0.023 \\
\hline & \multicolumn{3}{|c|}{$\begin{array}{l}\text { LAD that arise from RSV- anterior to } \\
\text { PA }\end{array}$} & A4b3 & 2 & 0.012 \\
\hline & \multirow{2}{*}{\multicolumn{2}{|c|}{$\begin{array}{l}\text { LCX that arises } \\
\text { from RSV }\end{array}$}} & $\begin{array}{l}\text { Posterior } \\
\text { atrioventricular } \\
\text { groove }\end{array}$ & $\mathrm{A} 4 \mathrm{c} 1$ & 1 & 0.006 \\
\hline & & & Retroaortic & $\mathrm{A} 4 \mathrm{c} 2$ & 39 & 0.226 \\
\hline & \multirow{4}{*}{\multicolumn{2}{|c|}{$\begin{array}{l}\text { LCA that arises } \\
\text { from RSV }\end{array}$}} & Retroaortic & $\mathrm{A} 4 \mathrm{~d} 2$ & 1 & 0.006 \\
\hline & & & Intraseptal & $\mathrm{A} 4 \mathrm{~d} 4$ & 4 & 0.023 \\
\hline & & & Anterior to PA & $\mathrm{A} 4 \mathrm{~d} 5$ & 1 & 0.006 \\
\hline & & & $\begin{array}{l}\text { Posterior } \\
\text { atrioventricular } \\
\text { groove }\end{array}$ & A4d1 & 1 & 0.006 \\
\hline & \multicolumn{3}{|c|}{ Single coronary artery } & A5 & 10 & 0.058 \\
\hline \multicolumn{4}{|c|}{ Anomalies of intrinsic coronary arterial anatomy } & $\mathrm{B}$ & 26 & 0.151 \\
\hline \multicolumn{4}{|l|}{ Split RCA } & B10a & 8 & 0.046 \\
\hline \multicolumn{4}{|l|}{ Split LAD } & $\mathrm{B} 11 \mathrm{~b}$ & 1 & 0.006 \\
\hline \multicolumn{4}{|l|}{ Coronary hypoplasia } & B5 & 1 & 0.006 \\
\hline \multicolumn{4}{|l|}{ Intramural coronary artery } & B6 & 16 & 0.093 \\
\hline \multicolumn{4}{|l|}{ Anomalies of coronary termination } & $\mathrm{C}$ & 35 & 0.203 \\
\hline \multirow{3}{*}{\multicolumn{2}{|c|}{ Coronary cameral/ Coronary to PA fistula }} & To right $\mathrm{v}$ & entricle & $\mathrm{C} 2 \mathrm{a}$ & 15 & 0.087 \\
\hline & & To right a & rium & $\mathrm{C} 2 \mathrm{~b}$ & 13 & 0.075 \\
\hline & & others & & $\mathrm{C} 2$ & 7 & 0.041 \\
\hline \multicolumn{4}{|l|}{ Anomalous anastomatic vessels } & $\mathrm{D}$ & 3 & 0.017 \\
\hline
\end{tabular}


LAD- Left Anterior Descending Artery; LCX- Left Circumflex artery; LSV- Left Sinus of Valsalva; PA- Pulmonary artery; PSV- Posterior Sinus of Valsalva; RCA- Right Coronary Artery; RSV- Right Sinus of Valsalva.

Functional Classification- Amongst the patients with CAAs, 204 (79.4\%) (Prevalence, 1.183\%) had benign anomalies while $20.6 \%$ (prevalence, $0.307 \%$ ) of patients had malignant anomalies. Malignant anomalies were detected extremely significantly more commonly in patients younger than 40 years than that in patients older than 40 years $(\mathrm{p}<0.0001)$.

\title{
Evaluation of CAAs on different modalities
}

Absent left main trunk- CAG was performed in all 55 patients with absent left main trunk. It detected the anomaly in 54 patients. Amongst those 55 patients, 37 patients also underwent MDCTA and the anomaly was identified in all those patients. For diagnosis of anomalous separate origin of LAD and LCX; CAG and MDCTA were equivalent with no significant difference $(\mathrm{p}=1.0)$. Origin of LAD and malignant intramural course were not identified in one patient with CAG.

\begin{abstract}
Anomalous location of coronary ostium within aortic root or near proper aortic sinus of Valsalva-Thirty-five patients had this anomaly. Invasive CAG was performed in 21 patients amongst those. It detected the anomaly in only 12 patients with a sensitivity of 58.3\%. MDCTA detected the anomaly in all 32 patients in whom it was performed. It had sensitivity of $100 \%$ for detection of this anomaly. Both, CAG and MDCTA had specificity of 100\%. For detection of anomalous origin of from similar sinus, MDCTA was better than CAG $(p=0.0001)$.
\end{abstract}

ACAOS- Amongst 87 patients with ACAOS, CAG was performed in 78 patients. It detected the anomaly in 76 patients with sensitivity of $98.6 \%$ and specificity of $100 \%$. However, it delineated the course properly in only 73 patients. On the contrary, MDCTA detected and delineated the course in all 73 patients in whom it was performed. So, it had a sensitivity of $100 \%$ and specificity of $100 \%$ for ACAOS. For ACAOS, the difference between diagnostic accuracy of CAG and MDCTA was not significant $(\mathrm{p}=0.49)$. Proper delineation of course after anomalous origin was significantly better with MDCTA than with CAG $(\mathrm{p}=0.05)$.

Intra-myocardial course- Intra-myocardial course of a coronary artery was there in 16 patients, out of which 15 patients underwent CAG. The anomaly was detected in 13 patients amongst those with a sensitivity of $88.89 \%$ and specificity of $100 \%$. MDCTA was performed in 12 patients and the anomaly was diagnosed in all those patients with a sensitivity of $100 \%$ and specificity of $100 \%$. CAG and MDCTA were comparable for diagnosis of myocardial bridge, and the difference was statistically insignificant $(\mathrm{p}=0.49)$. However, MDCTA delineated the intra-myocardial course (length of segment and depth) significantly better than CAG $(\mathrm{p}=0.0002)$.

Anomalies of coronary termination-Thirty-four out of 35 patients with coronary fistulae underwent CAG. This CAA was diagnosed in all those patients with CAG but the proper course was delineated in only 31 patients. MDCTA was performed in 33 patients. The CAA was diagnosed in 32 patients amongst those and the course of fistulous tract was delineated in all those 32 patients.

For diagnosis and course delineation of termination anomalies, CAG and MDCTA were equivalent ( $\mathrm{p}=0.49$ and 0.61 respectively). Echocardiography had sensitivity of 51\%, specificity of $99.9 \%$, for entire population. However, in pediatric age group, it had sensitivity of $92.8 \%$, specificity of $99.6 \%$. Its diagnostic accuracy for anomalous termination was very significantly higher in pediatric population $(<12$ years) than that in adults $(\mathrm{p}=0.0016)$ and in patients with proximal and larger fistulae than in those with smaller fistulae from distal vessels and branches $(\mathrm{p}<0.0001)$.

Anomalous anastomotic vessels-Out of 3 patients with abnormal anastomotic vessels, all 3 had their anomalies detected on CAG and 2 had the anomalies apparent on MDCTA. For diagnosis of abnormal anastomotic vessels, CAG had higher sensitivity $(100 \%)$ than that with MDCTA (66.67\%). Both had equal specificity (100\%). Proper course delineation of abnormal anastomotic vessel was successful in 2 patients with both of these modalities. For detection and proper delineation of course, the difference between MDCTA and CAG was statistically insignificant $(\mathrm{p}=1.0)$. 
Comparison of different modalities-The yield of echocardiography negatively correlated with age ( $\mathrm{r}=-0.6)$. Mean heart rate at the time of MDCTA was $74.37 \pm 8.21$ beats per minute (bpm), which was very significantly lower than mean heart rate of $85.44 \pm 15.23 \mathrm{bpm}$ during $\mathrm{CAG}(\mathrm{p}=0.0001)$. Need of per procedural beta-blockers to control heart rate was significantly higher with MDCTA than that with CAG $(\mathrm{p}<0.0001)$. Mean fluoroscopy-time with MDCTA $(2.28 \pm 0.82$ $\mathrm{min}$ ) was significantly lower than that with CAG (3.44 $\pm 2.5 \mathrm{~min})(\mathrm{p}=0.0001)$. Radiation exposure with $\mathrm{CAG}, 7.3 \pm 2 \mathrm{mSv}$, was lower than that with MDCTA, $14.5 \pm 3 \mathrm{mSv}(\mathrm{p}<0.0001)$. Radiation exposure for ACAOS was more than that for other anomalies with CAG ( $\mathrm{p}<0.001)$, but not with MDCTA ( $\mathrm{p}=0.18$ ). (Figure-3) Radiation exposure with CAG correlated with CAA score $(r=0.3)$, especially for origin and course anomalies $(r=0.6)$. With MDCTA, the radiation exposure did not correlate with CAA score $(\mathrm{r}=-0.019)$. (Figure-4) Mean contrast-expenditure during CAG $(65.55 \pm 19.9 \mathrm{ml})$ and MDCTA $(63.15 \pm 15.6 \mathrm{ml})$ were not different $(\mathrm{p}=0.52)$. Contrast-expenditure correlated with CAA score with CAG for adults ( $\mathrm{r}=0.42)$ but not with MDCTA $(\mathrm{r}=-0.04)$.

Figure-3: Bar diagram showing radiation exposure with different coronary anomalies with invasive $\mathrm{X}$-ray angiogram and computed tomogram

A1- Absent left main trunk; A2- Anomalous location of coronary ostium within aortic root or near proper aortic sinus of Valsalva; A3- Anomalous location of coronary ostium outside normal coronary aortic sinuses; A4- Anomalous location of coronary ostium at improper sinus, A5- Single coronary artery; B- Anomalies of intrinsic coronary arterial anatomy; C- Coronary cameral/ Coronary to pulmonary artery fistula; D- Anomalous anastomatic vessels

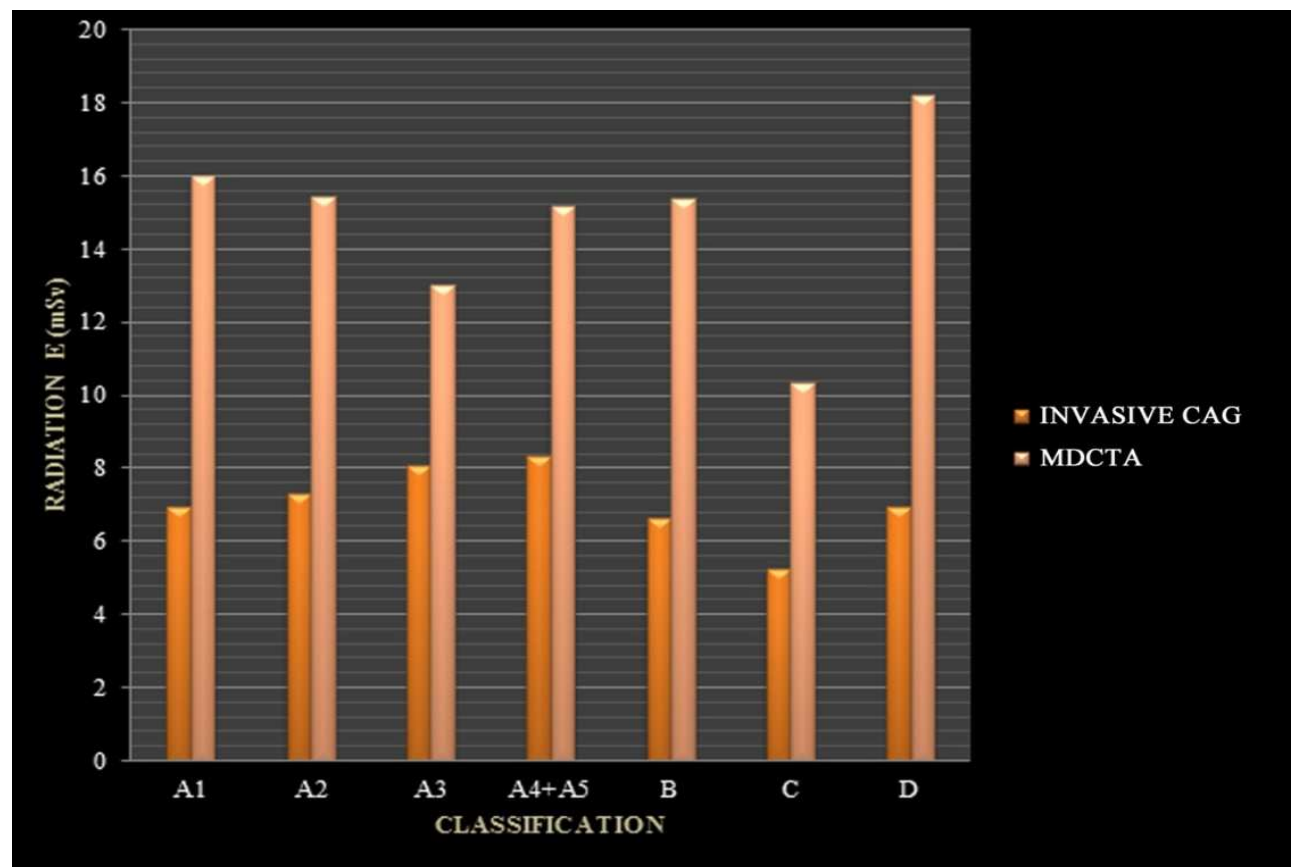

Figure-4: Scattered diagrams showing correlation of radiation exposure (E) with Coronary Artery Anomaly score
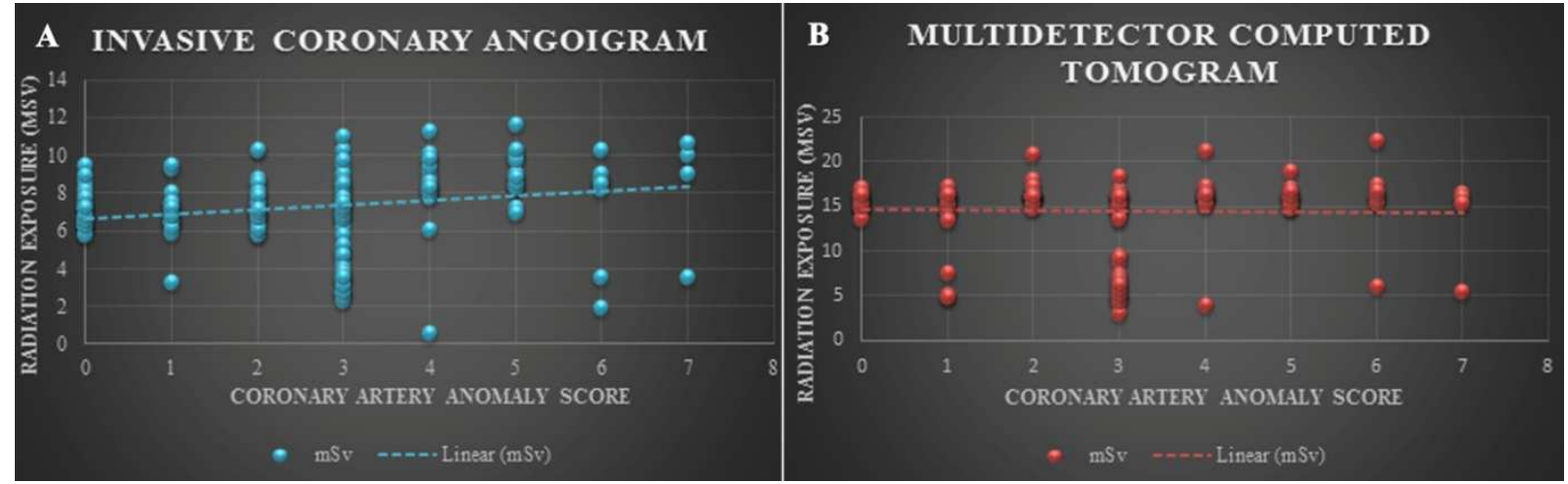
A: Correlation on invasive coronary angiogram $(r=0.3)$

B: Correlation on multidetector computed tomographic angiogram $(r=-0.019)$

\section{Discussion}

Prevalence-According to the current literature, CAAs occur in approximately $1 \%$ of the general population. This prevalence is derived from invasive CAG studies performed for suspected CAD. Necropsy studies report even lower numbers: Alexander and Griffith observed only 54 CAAs in 18,950 cases (0.3\%).[2] These studies were limited by entry bias and lack of clear diagnostic criteria, which both are prerequisites for defining the true prevalence in a population. The first study adopting strict criteria for assessing CAAs was performed by Angelini and co-workers [10]. They reported a $5.64 \%$ prevalence of CAAs, which was higher than the usually cited prevalence derived from angiographic reports, but comparable to one of the first reports using 64-slice CT [10]. The later study reported a prevalence of $7.9 \%$ of CAAs of origin and further course, in mainly symptomatic patients [10]. De Jonge and co-workers also described a prevalence of $7 \%$ of CAAs including coronary fistulae [11]. In our study, an overall of 257 patients (1.49\%) with CAAs were identified amongst 17,245 patients. This result is quite similar to that observed in a large angiographic series [12] as well as in two large MDCTA studies dealing either with 4- or 16-slice CT scanner and including 1758 patients [6] or with 64-slice CT in 1495 patients [13]. However, even such large studies do not reflect general population as only symptomatic patients with indications for either CAG or MDCTA were considered. Our findings are similar to previously published angiographic studies [10,13,14] although Wilkins et al (1988), [15] as well as Yamanaka et al (1990),[12] in the largest angiographic trial including 126,595 patients, reported a different prevalence in their study population. Nevertheless these inconsistent findings concerning the prevalence of CAAs and, moreover, different subgroups suggest that the described numbers are only relevant for those particular study populations. These discrepancies in reported prevalence might be caused by referral bias. Some of these patients with CAAs might have been or were referred because of known presence of CAA and not because of unrelated factors as in the general population. Therefore, a general conclusion for asymptomatic individuals cannot be drawn. Recently Cademartiri and colleagues (2008) reported a $1.5 \%$ prevalence of ACAOS as detected by MDCTA in a series of 543 patients [16] Our study also showed the results similar to that CT angiographic study.

The findings from angiograms performed for suspected ischemic disease indicate that CAAs were more common in women (7.6\% versus $4.8 \%$ in men; $p=0.01)$ [10]. However, the difference between the prevalence in two genders was statistically insignificant in our study.

Classification-CAAs were found in 1,686 patients (1.3\% incidence) undergoing CAG at the Cleveland Clinic Foundation from 1960 to 1988 . Of the 1,686 patients, 1,461 (87\%) had anomalies of origin and distribution, and 225 (13\%) had coronary artery fistulae [12]. Similarly, $88.72 \%$ of our patients had anomalies of origin and/or course; while, $11.3 \%$ had anomalies of termination, anastomosis.

Anomalies of origination and course- Table-2 shows the prevalence of CAAs, according to imaging modalities in various studies,[8,12,17-32] including our study. For anomalies of coronary structure like myocardial bridge; depth and length of intra-myocardial segment are important for risk scoring and stratification [9]. In our study, MDCTA was better than CAG for the diagnosis of anomalous location of coronary ostium within aortic root or near proper aortic sinus. Both were equivalent for identification of absent left main trunk, ACAOS and myocardial bridge. However, MDCTA was better than CAG for proper course delineation for ACAOS and intramural coronary artery, in our study.

Anomalies of coronary termination and anastomosis-Owing to the potentially complex 3-dimensional natures of these anomalies, conventional CAG, not infrequently, incompletely delineates the anatomical course of the coronary artery. CAG for fistulous anomalies requires a catheter in the right ventricular outflow tract and multiple views to define the course [33]. Reliable, complete, non-invasive assessment (or indeed reliable exclusion) of CAAs is therefore desirable and advantageous [34]. There was no significant difference CAG and MDCTA for identification of CAAs of termination and anastomosis in our study. 
Table-2: Prevalence of CAAs in different studies according to imaging modalities

ACAOS- Anomalous Coronary Artery from Opposite Sinus; ALCAPA- Anomalous Left Coronary Artery from Pulmonary artery; CAA- Coronary Artery Anomaly; CAG-Coronary Angiogram; CTCA- Computed Tomographic Coronary Angiogram; LAD- Left Anterior Descendong Artery; LCA- Left Coronary Artery; LCX- Left Circumflex Artery; LSV- Left Sinus of Valsalva; PSV- Poterior Sinus of Valsalva; RCA- Right Coronary Artery; RSV- Right Sinus of Valsalva

\begin{tabular}{|c|c|c|c|c|c|c|c|c|c|c|c|c|c|}
\hline \multirow[t]{2}{*}{ Study } & \multirow{2}{*}{$\begin{array}{l}\text { Detection } \\
\text { Modality }\end{array}$} & \multirow{2}{*}{$\begin{array}{l}\text { Study } \\
\text { Population }\end{array}$} & \multicolumn{11}{|c|}{ Prevalence (\%) } \\
\hline & & & U & 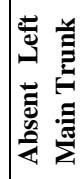 & 热 & 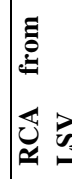 & 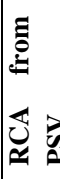 & 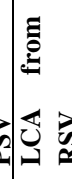 & 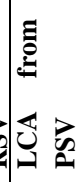 & 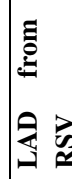 & 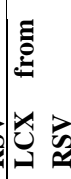 & $=\frac{\mathscr{m}}{\tilde{E}}$ & 岁 \\
\hline Yamanaka et $\mathrm{al}^{12}$ & CAG & 126,595 & 1.3 & 0.41 & 0.155 & 0.107 & 0.003 & 30.017 & 0.0008 & 0.030 & & 1.12 & 0.008 \\
\hline Lipsett et $\mathrm{al}^{17}$ & Autopsy & 7,857 (pediatric) & 0.5 & - & 0.216 & - & & - & - & | & ] & - & - \\
\hline${\text { Frescura et } \mathrm{al}^{18}}^{18}$ & Autopsy & $\begin{array}{c}1200 \text { (Congenital } \\
\text { heart disease) }\end{array}$ & 2.2 & - & 1.0 & 0.58 & & 0.33 & 0.083 & - & 0.25 & & 0.004 \\
\hline Davis et $\mathrm{al}^{19}$ & $\begin{array}{l}\text { Echocardi } \\
\text { ography }\end{array}$ & 2,388 (pediatric) & - & - & 0.167 & 0.084 & & 0.084 & $4-$ & - & - & - & - \\
\hline $\begin{array}{l}\text { Harikrishnan et } \\
\mathrm{al}^{20}\end{array}$ & CAG & 7,400 & $\begin{array}{l}0.460 \\
\text { (excluding, } \\
\text { congenital } \\
\text { heart } \\
\text { diseases } \\
\text { fistulae) }\end{array}$ & 0.162 & 0.216 & 0.095 & & 0.028 & - & 0.014 & 0.081 & $1-$ & - \\
\hline Gianluca et $\mathrm{al}^{21}$ & CAG & 5,100 & 1.216 & - & 0.294 & 0.235 & & 0.039 & - & 5 & & 0.039 & - \\
\hline Aydinlar et $\mathrm{al}^{22}$ & CAG & 12,059 & 0.829 & - & 0.232 & 0.058 & & 0.075 & 5 & 0.008 & 0.091 & 0.0414 & - \\
\hline Angelini et $\mathrm{al}^{8}$ & CAG & 1950 & 5.64 & 0.67 & 1.07 & 0.92 & & 0.15 & - & 5 & 0.67 & 0.87 & - \\
\hline von Ziegler et $\mathrm{al}^{23}$ & CTCA & 748 & 2.3 & - & - & 1.070 & & 0.134 & t. & 5 & 0.936 & $6-$ & - \\
\hline Ten Kate et $\mathrm{al}^{24}$ & CTCA & 1000 & 0.9 & - & 0.8 & 0.05 & & 0.02 & - & - & 0.01 & - & 0.01 \\
\hline Kosar et $\mathrm{al}^{25}$ & CTCA & 700 & 1.4 & 0.4 & 1.0 & 0.5 & & 0.2 & $F$ & - & 0.1 & - & - \\
\hline Yildiz et $\mathrm{al}^{26}$ & CAG & 12,457 & 0.9 & 0.57 & 0.168 & 0.080 & & 0.008 & tit & 0.000 & 0.080 & 0.096 & - \\
\hline${\text { Eid et } \mathrm{al}^{27}}^{27}$ & CAG & 4,650 & $\begin{array}{l}0.73 \\
\text { (excluding } \\
\text { ALCAPA, } \\
\text { fistulae, and } \\
\text { aneurysms) }\end{array}$ & - & 0.387 & 0.194 & & 0.108 & & 0.022 & 0.065 & & - \\
\hline Zhang et $\mathrm{al}^{28}$ & CTCA & 1,879 & 1.3 & 0.85 & 0.905 & 0.639 & & 0.053 & 0.160 & 0.000 & 0.053 & - & - \\
\hline Karabay et $\mathrm{al}^{29}$ & CTCA & 745 & 4.96 & 0.93 & - & - & 0.13 & & - & - & 0.79 & 0.13 & - \\
\hline Ghadri et $\mathrm{al}^{30}$ & CTCA & 1759 & 7.85 & 0.909 & & 0.625 & & & 5 & 0.227 & 1.08 & 0.341 & 0.114 \\
\hline Ghadri et $\mathrm{al}^{30}$ & CAG & 9782 & 2.08 & 0.746 & - & 0.133 & & & - & 0.076 & 0.005 & 0.184 & 0.01 \\
\hline Altin et $\mathrm{al}^{31}$ & CAG & 5548 & 2.7 & 0.9 & - & 0.72 & & 0.018 & - & - & & 0.2 & - \\
\hline Gräni et $\mathrm{al}^{32}$ & CTCA & 5634 & 2.6 & 0.48 & 1.17 & 0.59 & 0.02 & 0.04 & 0.09 & 0.08 & 0.38 & 0.09 & 0.02 \\
\hline Present study & $\begin{array}{l}\text { Echocardi } \\
\text { ography, } \\
\text { CAG, } \\
\text { CTCA }\end{array}$ & 17245 & 1.49 & 0.319 & 0.499 & 0.197 & & 0.075 & & 0.012 & 0.231 & 0.203 & 0.029 \\
\hline
\end{tabular}


Functional Classification-Most CAAs did not result in signs, symptoms, or complications, and usually were discovered as incidental findings at the time of catheterization. Eighty-one percent were benign anomalies whereas; other anomalies were potentially serious in a study [12]. In our study, $79.4 \%$ patients had benign anomalies and $20.6 \%$ patients had potentially serious anomalies.

\section{Imaging Modalities}

Echocardiography-Echocardiography is an alternative noninvasive imaging modality. Transthoracic echocardiography is a practical and often diagnostic test if specific attention is paid to the coronary arteries. Evaluation by echocardiography is limited to the proximal part of the coronary arteries [35]. Similarly, in our study, the diagnostic yield of echocardiography was more in pediatric patients and in those with proximal and larger abnormalities than in adults and those with distal and smaller anomalies.

Invasive CAG- CAG has traditionally been the imaging test of choice for the diagnosis and characterization of CAAs. The presence of a CAA can be a differential diagnosis in patients with suspected coronary disease, chest pain, or syncope. Accurate diagnosis of CAAs with CAG, however, is limited by the inability to define the anatomic course in relation to surrounding structures. Owing to the potentially complex three-dimensional nature of these anomalies, CAG, not infrequently, incompletely delineates the anatomical course of the coronary artery [33]. However, the presence of an anomalous coronary artery origin is sometimes only suspected after the invasive procedure, particularly in the case of unsuccessful engagement or visualization of a coronary artery. In addition, the declining use of pulmonary artery catheters during routine x-ray CAG has made it more difficult to discern the anterior versus the posterior trajectory of the anomalous vessels. The information obtained via catheter-based CAG pertains to the coronary arterial lumen alone [36]. In one study, CAG alone achieved correct identification of the abnormality in only $53 \%(p=0.016)[1]$.

Table-3: Comparisons of CTA and invasive CAG for CAA Evaluation on different studies

\begin{tabular}{|c|c|c|c|}
\hline Study & Imaging Technique & $\begin{array}{l}\text { Correctly Classified } \\
\text { CAA/ Total patients with CAA }\end{array}$ & Percentage \\
\hline Ropers et al $^{7}$ & EBT & $29 / 30$ & 97 \\
\hline Memisoglu et $\mathrm{al}^{37}$ & EBT & $14 / 14$ & 100 \\
\hline Shi et $\mathrm{al}^{38}$ & MDCT & $16 / 16$ & 100 \\
\hline Schmid et $\mathrm{al}^{39}$ & $16 \mathrm{MSCT}$ & $35 / 35$ & 100 \\
\hline Datta et $\mathrm{al}^{40}$ & 16 MSCT & $20 / 20$ & 100 \\
\hline Schmitt et al ${ }^{41}$ & 16 MDCT & $44 / 44$ & 100 \\
\hline Sato et $\mathrm{al}^{42}$ & MSCT & $5 / 5$ & 100 \\
\hline van Ooijen et al ${ }^{43}$ & $16 \mathrm{MSCT}$ & $13 / 13$ & 100 \\
\hline Berbarie et al $^{44}$ & MDCT & $16 / 16$ & 100 \\
\hline Deibler et $\mathrm{al}^{45}$ & MDCT & $8 / 9$ & 89 \\
\hline Kacmaza et al $^{1}$ & ECG gated 16 MDCT & $23 / 23$ & 100 \\
\hline Present study & ECG gated 128 MDCT & $206 / 207$ & 99.5 \\
\hline
\end{tabular}

CAA- Coronary Artery Anomaly; CT- Computed Tomography; EBT- Electron Beam Tomography; ECGElectrocardiogram; MDCT- Multidetector CT; MSCT- Multislice CT

CTA- On comparison with invasive CAG, EBCT correctly identifies all normal controls and all patients with CAAs. The anatomic course of the coronary arteries was correctly classified with 97\% accuracy, including ACAOS and coronary cameral fistula in a study of 30 patients. That study demonstrated that contrast-enhanced EBCT is a reliable noninvasive technique to identify CAAs and their course [35]. Multiple published series (Table-3) for comparison of coronary CTA data with CAG for evaluation of CAAs exist [1,7,37-45]. Early reports of using CTA to evaluate coronary artery have emphasized EBCT. MDCTA is a new imaging method to delineate clearly the origin and course of the CAAs. As we 
have demonstrated in this study, MDCTA demonstrates precise origin and course with excellent spatial resolution. Some reports in current literature have supported our findings [1]. CTA is recommended for evaluation of suspected CAAs $[38,46]$. The assessment of anomalous coronary artery origin with cardiac CT has been shown to be accurate and of benefit in detecting and characterizing CAAs compared to CAG [7,36,39]. Radiation exposure, though higher with MDCTA than that with CAG; does not correlate with complexity of CAA in our study.

Other Modalities- The coronary MRI studies uniformly reported excellent specificity, sensitivity, accuracy; superiority over CAG with superior reconstruction capabilities with similarly excellent results in patients with CAAs [14,36,47]. Its limitations are low spatial resolution, artifacts, incomplete visualization of the distal arterial course, technical challenges, time consumption especially in comparison to MDCTA [16,47]. Intravascular Ultrasound (IVUS) gives idea regarding size and shape of ostium, tengentiality of proximal part of coronary artery in cases with abnormal origin. Virtual angioscopy analysis is useful for visualization and measurement of the coronary ostia, and localization relative to the intercoronary commissure, which is not possible with CAG. Distinct aortic origins of the RCA and LCA were seen in all 56 studies with virtual angioscopy [48].

Limitations- A relatively small number of patients and a retrospective nature of the study make generalization of results and conclusions questionable. The patients who underwent coronary work-up were actually referred for evaluation for symptoms. So they may not truly represent the community as it may also include asymptomatic individuals. Other imaging modalities e.g. coronary MRI, IVUS etc. were not evaluated. This study compared only anatomical modalities of coronary evaluation. Physiological studies like nuclear imaging, stress testing which give more information regarding impact of that particular anomaly; were not included.

\section{Conclusion}

Echocardiography adequately detects proximal CAAs, especially in pediatric patients. Its usefulness declines with increased body mass due to acoustic factors. CAG and MDCTA are comparable for detection of most CAA (except high origin near proper sinus). MDCTA better delineates 3-dimensional natures of anomalies and course. Radiation exposure is significantly more with MDCTA than with CAG, but this is not correlated to complexity of anomaly in contrast to CAG. MDCTA can be used for detection and delineation of most of CAA if patient is not at increased radiation risk (e.g. extremes of age) and who are prone to complications of CAG.

Source of support: U. N. Mehta Institute of Cardiology and Research Centre (affiliated to the B.J. medical college, Ahmedabad, India)

No conflict of interest and no relationship with industry

Funding: Nil, Conflict of interest: None initiated, Permission from IRB: Yes

\section{References}

1. Kacmaza F, Ozbulbulb NI, Alyana O, Madena O, Demira AD, Balbaya Y, Erbaya AR , Ataka R, Senena $\mathrm{K}$, Olcerb T, Ilkayc E. Imaging of coronary artery anomalies: the role of multidetector computed tomography. Coron Artery Dis. 2008 May; 19(3):2039. doi: 10.1097/MCA.0b013e3282f528f1

2. Alexander RW, Griffith GC. Anomalies of the coronary arteries and their clinical significance. Circulation. 1956 Nov; 14(5):800-5.

3. Engel HJ, Torres C, Page HL Jr. Major variations in anatomical origin of the coronary arteries: angiographic observations in 4,250 patients without associated congenital heart disease. Cathet Cardiovasc Diagn. 1975;1(2):157-69. doi: 10.1002/ccd.1810010205

4. Kaku B, Kanaya H, Ikeda M, Uno Y, Fujita S, Kato $\mathrm{F}$, Oka T. Acute inferior myocardial infarction and coronary artery spasm in a patient with an anomalous origin of the right coronary arteryfrom the left sinus of Valsalva. Jpn Circ J. 2000 Aug; 64(8):641-3.

5. Benge W, Martins JB, Funk DC. Morbidity associated with anomalous origin of the right coronary artery from the left sinus of Valsalva. Am Heart J. 1980 Jan; 99(1):96-100.

6. Basso C, Maron BJ, Corrado D, Thiene G. Clinical profile of congenital coronary artery anomalies with 
origin from the wrong aortic sinus leading to sudden in young competitive athletes. J Am Coll Cardiol 2000 May; 35(6): 1493-501. doi: 10.1016/S07351097(00)00566-0.

7. Ropers D, Moshage W, Daniel WG, Jessl J, Gottwik M, Achenbach S. Visualization of coronary artery anomalies and their anatomic course by contrastenhanced electron beam tomography and threedimensional reconstruction. Am J Cardiol. 2001 Jan; 87(2):193-7.

8. Angelini P. Coronary artery anomalies: an entity in search of an identity. Circulation. 2007 Mar 13;115(10):1296-305.

9. Rigatelli G, Rigatelli A, Cominato S, PaninS, Nghia NT, Faggian G. A clinical-angiographic risk scoring system for coronary artery anomalies. Asian Cardiovascular \& Thoracic Annals. 2012; 20(3) 299303.

10. Angelini P. Coronary artery anomalies--current clinical issues: definitions, classification, incidence, clinical relevance, and treatment guidelines. Tex Heart Inst J. 2002; 29(4):271-8.

11. de Jonge GJ, van Ooijen PMA, Piers LH, Dikkers R, Tio RA, Willems TP, van den Heuvel AFM, Zijlstra F, Oudkerk M. Visualization of anomalous coronary arteries on dual-source computed tomography. Eur Radiol. $2008 \quad$ Nov; 18(11): 2425-32. doi:10.1007/s00330-008-1110-y

12. Yamanaka O, Hobbs RE. Coronary artery anomalies in 126,595 patients undergoing coronary arteriography. Cathet Cardiovasc Diagn. 1990; 21(1): 28-40. doi: 10.1002/ccd.1810210110.

13. Golding SJ, Jurik AG, Leonardi M, van Meerten EvP, Geleijns J, Jessen KA, Panzer W, Shrimpton PC, Tosi G. European Guidelines on Quality Criteria for Computed Tomography. EUR 16262 EN. 1999. http://www.drs.dk/guidelines/ct/quality/mainindex.htm.

14. Topaz O, DeMarchena EJ, Perin E, Sommer LS, Mallon SM, Chahine RA. Anomalous coronary arteries: angiographic findings in 80 patients. Int J Cardiol. 1992 Feb;34(2):129-38.
15. Wilkins CE, Betancourt B, Mathur VS, Massumi A, De Castro CM, Garcia E, Hall RJ. Coronary artery anomalies: a review of more than 10,000 patients from the Clayton Cardiovascular Laboratories. Tex Heart Inst J. 1988; 15(3):166-73.

16. Cademartiri F, La Grutta L, Malagò R, Alberghina F, Meijboom WB, Pugliese F, Maffei E, Palumbo AA, Aldrovandi A, Fusaro M, Brambillia V, Coruzzi P, Midiri M, Mollet NRA, Krestin GP. Prevalence of anatomical variants and coronary anomalies in 543 consecutive patients studied with 64-slice CT coronary angiography. Eur Radiol. 2008 Apr; 18(4):781-91. doi: 10.1007/s00330-007-0821-9

17. Lipsett J, Cohle SD, Berry PJ, Russell G, Byard RW. Anomalous Coronary Arteries: A Multicenter Pediatric Autopsy Study. Pediatr Pathol. 1994 Mar-Apr; 14(2):287-300.

18. Frescura C, Basso C, Thiene G, Corrado D, Pennelli $\mathrm{T}$, Angelini A, Daliento L. Anomalous Origin of Coronary Arteries and Risk of Sudden Death: a Study Based on an Autopsy Population of Congenital Heart Disease. Hum Pathol. 1998 Jul; 29(7):689-95. doi: http://dx.doi.org/10.1016/S0046-8177(98)90277-5

19. Davis JA, Cecchin F, Jones TK, Portman MA. Major Coronary Artery Anomalies in a Pediatric Population: Incidence and Clinical Importance. J Am Coll Cardiol. 2001 Feb; 37(2): 593-7.

20. Harikrishnan S, Jacob SP, Tharakkan I, Titus T, Kumar VK, Bhat A, Sivasankaran S, Bimal F, Moorthy KM, Kumar RP. Congenital Coronary Anomalies of Origin and Distribution in Adults: a Coronary Arteriographic Study. Indian Heart J. 2002 May-Jun; 54(3):271-275.

21. Gianluca R, Giorgio D, Paolo R, Daniela B, Daniele R, Attilio B, Gabriele L, Giorgio R. Congenital Coronary Artery Anomalies Angiographic Classification Revisited. Int J Cardiovasc Imaging. 2003 Oct; 19(5):361-6. doi: 10.1023/A:1025806908289

22. Aydinlar A, Cicek D, Senturk T, Gemici K, Serdar OA, Kazazoglu AR, Kumbay E, Cordan J. Primary Congenital Anomalies of the Coronary Arteries: a Coronary Angiographic Study in Western Turky. Int Heart J. 2005 Jan; 46(1): 97-103. 
23. von Ziegler F, Pilla M, McMullan L, Panse P, Leber AW, Wilke N, Becker A. Visualization of anomalous origin and course of coronary arteries in 748 consecutive symptomatic patients by 64-slice computed tomography angiography. BMC Cardiovasc Disord. 2009 Dec; 9: 54. doi: 10.1186/1471-2261-9-54.

24. Ten Kate GJ, Weustink AC, de Feyter PJ. Coronary artery anomalies detected by MSCT-coronary angiography in the adult. Neth Heart J. 2008 Nov;16(11):369-75.

25. Koşar P, Ergun E, Oztürk C, Koşar U. Anatomic variations and anomalies of the coronary arteries: 64slice CT angiographic appearance. Diagn Interv Radiol. 2009 Dec;15(4):275-83. doi: 10.4261/13053825.DIR.2550-09.1 Epub 2009 Dec 2.

26. Yildiz A, Okcun B, Peker T, Arslan C, Olcay A, Bulent Vatan M. Prevalence of coronary artery anomalies in 12,457 adult patients who underwent coronary angiography. Clin Cardiol. 2010 Dec;33(12):E60-4. doi: 10.1002/clc.20588

27. Eid AH, Itani Z, Al-Tannir M, Sayegh S, Samaha A. Primary Congenital Anomalies of the Coronary Arteries and Relation to Atherosclerosis: an Angiographic Study in Lebanon. Journal of Cardiothoracic Surgery. 2009 Oct; 4:58. doi:10.1186/1749-8090-4-58.

28. Zhang LJ, Yang GF, Huang W, Zhou CS, Chen P, Lu GM. Incidence of anomalous origin of coronary artery in 1879 Chinese adults on dual-source CT angiography. Neth Heart J. 2010 Oct;18(10):466-70.

29. Karabay KO, Yildiz AM, Geceer G, Uysal E, Bagirtan B. The Incidence of Coronary Anomalies on Routine Coronary Computed Tomography Scans. Cardiovasc J Afr. 2013 Nov; 24(9):351-4. doi: 10.5830/CVJA-2013-066

30. Ghadri JR, Kazakauskaite E, Braunschweig S, Burger IA, Frank M, Fiechter M, Gebhard C, Fuchs TA, Templin C, Gaemperli O, Luscher TF, Schmied C, Kaufmann PA. Congenital Coronary Anomalies Detected by Coronary Computed Tomography Compared to Invasive Coronary Angiography. BMC Cardiovascular Disorders. 2014 July; 14:81. doi: 10.1186/1471-2261-14-81
31. Altin C, Kanyilmaz S, Koc S, Gursoy YC, Bal U, Aydinalp A, Yildirir A, Muderrisoglu H. Coronary Anatomy, Anatomic Variations and Anomalies: a Retrospective Coronary Angiography Study. Singapore Med J. 2015 Jun; 56(6):339-45. doi: 10.11622/smedj.2014193.

32. Gräni C, Benz DC, Schmied C, Vontobel J, Possner M, Clerc OF, Mikulicic F, Stehli J, Fuchs TA, Pazhenkottil AP, Gaemperli O, Kaufmann PA, Buechel RR. Prevalence and characteristics of coronary artery anomalies detected by coronary computed tomography angiography in 5634 consecutive patients in a single centre in Switzerland. Swiss Med Wkly. 2016 Apr; 146:w14294. doi:10.4414/smw.2016.14294

33. Armsby LR, Keane JF, Sherwood MC, Forbess JM, Perry SB, Lock JE. Management of coronary artery fistulae: patient selection and results of transcatheter closure. J Am Coll Cardiol. 2002 Mar; 39(6):1026-32.

34. Manghat NE, Morgan-Hughes GJ, Marshall AJ, Roobottom CA. Multidetector row computed tomography: imaging congenital coronary artery anomalies in adults. Heart. 2005 Dec; 91(12):1515-22. doi: 10.1136/hrt.2005.065979

35. Fernandes F, Alam M, Smith S, Khaja F. The role of transesophageal echocardiography in identifying anomalous coronary arteries. Circulation. 1993 Dec; 88(6):2532-40.

36. Bluemke DA, Achenbach S, Budoff M, Gerber TC, Gersh B, Hillis LD, Hundley WG, Manning WJ, Printz BF, Stuber M, Woodard PK. Noninvasive coronary artery imaging: magnetic resonance angiography and multidetector computed tomography angiography: a scientific statement from the american heart association committee on cardiovascular imaging and intervention of the council on cardiovascular radiology and intervention, and the councils on clinical cardiology and cardiovascular disease in the young. Circulation. 2008 July; 118(5):586-606. doi: 10.1161/CIRCULATIONAHA.108.189695

37. Memisoglu E, Hobikoglu G, Tepe MS, Norgaz T, Bilsel T. Congenital Coronary Anomalies in Adults: Comparison of Anatomic course visualization by catheter angiography and electron beam CT. Catheter Cardiovasc Interv. 2005 Sep; 66(1):34-42. doi: 10.1002/ccd.20444 
38. Shi H, Aschoff AJ, Brambs HJ, Hoffmann MH. Multislice CT imaging of anomalous coronary arteries. Eur Radiol. 2004 Dec;14(12):2172-81. Epub 2004 Oct 15

39. Schmid M, Achenbach S, Ludwig J, Baum U, Anders K, Pohle K, Daniel WG, Ropers D. Visualization of coronary artery anomalies by contrastenhanced multi-detector row spiral computed tomography. Int J Cardiol. 2006 Aug; 111(3):430-5. doi: 10.1016/j.ijcard.2005.08.027

40. Datta J, White CS, Gilkeson RC, Meyer CA, Kansal S, Jani ML, Arildsen RC, Read K. Anomalous coronary arteries in adults: depiction at multi-detector row CT angiography. Radiology. 2005 Jun; 235(3):812-8. doi: 10.1148/radiol.2353040314

41. Schmitt R, Froehner S, Brunn J, Wagner M, Brunner H, Cherevatyy O, Gietzen F, Christopoulos G, Kerber S, Fellner F. Congenital anomalies of the coronary arteries: imaging with contrast-enhanced, multidetector computed tomography. Eur Radiol. 2005 Jun; 15(6):1110-21. doi: 10.1007/s00330-005-2707-z

42. Sato Y, Inoue F, Matsumoto N, Tani S, Takayama T, Yoda S, Kunimasa, T, Ishii N, Uchiyama T, Saito S, Tanaka H, Furuhashi S, Takahashi M, Koyama Y. Detection of anomalous origins of the coronary artery by means of multislice computed tomography. Circ J. 2005 Mar; 69(3):320-4.

43. van Ooijen PM, Dorgelo J, Zijlstra F, Oudkerk M. Detection, visualization and evaluation of anomalous coronary anatomy on 16-slice multidetector-row CT. Eur Radiol. 2004 Dec;14(12):2163-71. Epub 2004 Sep 28

44. Berbarie RF, Dockery WD, Johnson KB, Rosenthal RL, Stoler RC, Schussler JM. Use of multislice computed tomographic coronary angiography for the diagnosis of anomalous coronary arteries. Am J Cardiol.
$2006 \quad$ Aug; $\quad 98(3): 402-6 . \quad$ doi:
10.1016/j.amjcard.2006.02.046

45. Deibler AR, Kuzo RS, Vohringer M, Page EE, Safford RE, Patron JN, Lane GE, Morin RL, Gerber TC. Imaging of congenital coronary anomalies with multislice computed tomography. Mayo Clin Proc. 2004 Aug; 79(8):1017-23.

46 .Hendel RC, Patel MR, Kramer CM, Poon M, Carr JC, Gerstad NA, Gillam LD, Hodgson JM, Kim RJ, Lesser JR, Martin ET, Messer JV, Redberg RF, Rubin GD, Rumsfeld JS, Taylor AJ, Weigold WG, Woodard PK, Brindis RG, Douglas PS, Peterson ED, Wolk MJ, Allen JM. Accf/acr/scct/scmr/asnc/nasci/scai/sir 2006 appropriateness criteria for cardiac computed tomography and cardiac magnetic resonance imaging: A report of the american college of cardiology foundation quality strategic directions committee appropriateness criteria working group, american college of radiology, society of cardiovascular computed tomography, society for cardiovascular magnetic resonance, american society of nuclear cardiology, north american society for cardiac imaging, society for cardiovascular angiography and interventions, and society of interventional radiology. $\mathrm{J}$ Am Coll Cardiol. 2006 Oct; 48(7):1475-97. doi: 10.1016/j.jacc.2006.07.003.

47. McConnell MV, Ganz P, Selwyn AP, Li W, Edelman RR, Manning WJ. Identification of anomalous coronary arteries and their anatomic course by magnetic resonance coronary angiography. Circulation. 1995 Dec 1;92(11):3158-62.

48. Harris MA, Weinberg PM, Shin DC, Whitehead KK, Gillespie MJ, Dori Y, Spray TL, Fogel MA. Virtual Angioscopy Identifies Abnormal Coronary Ostial Morphology in Patients With Anomalous Origin of a Coronary Artery From the Contralateral Sinus of Valsalva. Circulation. 2011; 124: A16138.

\section{How to cite this article?}

Raval A, Jadhav N, Prajapati J, Rawal J, Garg R, Shah K, Patel I. Distribution of Coronary Artery Anomalies and Their Evaluation with Different Imaging Modalities. Int J Med Res Rev 2016;4(10):1807-1819.doi:10.17511/ijmrr. 2016.i10.17. 